\title{
Combinatorial treatment of curcumin or silibinin with doxorubicin sensitises high-risk neuroblastoma
}

\author{
Pamali Fonseka ${ }^{1, \#, ~ L a h i r u ~ G a n g o d a ', \#, ~ M o h a s h i n ~ P a t h a n ¹, ~ D i ~ G i a n n a t a l e ~ A n g e l a ², ~ S u r e s h ~ M a t h i v a n a n ~}{ }^{1}$ \\ 'Department of Biochemistry and Genetics, La Trobe Institute for Molecular Science, La Trobe University, Melbourne, Victoria \\ 3086, Australia. \\ ${ }^{2}$ Department of Hematology/Oncology, Bambino Gesù Children's Hospital, IRCCS, Rome 00165, Italy. \\ \#Authors contributed equally.
}

Correspondence to: Prof. Suresh Mathivanan, Department of Biochemistry and Genetics, La Trobe Institute for Molecular Science, La Trobe University, Bundoora, Victoria 3086, Australia. E-mail: s.mathivanan@latrobe.edu.au

How to cite this article: Fonseka P, Gangoda L, Pathan M, Angela DG, Mathivanan S. Combinatorial treatment of curcumin or silibinin with doxorubicin sensitises high-risk neuroblastoma. J Cancer Metastasis Treat 2020;6:7.

http://dx.doi.org/10.20517/2394-4722.2019.024

Received: 16 Aug 2019 First Decision: 20 Nov 2019 Revised: 17 Feb 2020 Accepted: 2 Mar 2020 Published: 13 Mar 2020

Science Editor: Godefridus J. Peters Copy Editor: Jing-Wen Zhang Production Editor: Jing Yu

\begin{abstract}
Aim: Neuroblastoma is a pediatric cancer of the sympathetic nervous system. Using various parameters including stage of the disease, amplification status of N-Myc, DNA index and histopathology, neuroblastoma can be stratified into low- and high-risk groups. Recent advances in treatment have significantly improved the survival rate of lowrisk neuroblastoma patients. However, the overall survival rate of high-risk neuroblastoma group, especially N-Myc amplified patients, is poor. Moreover, the survivors of both low- and high-risk neuroblastoma manifest adverse side effects to chemotherapy and thus their quality of life is impaired. Considering all these factors, there is an urgent need to develop therapeutic strategies with natural compounds to improve the survival rate and to reduce the side effects. In this study, we hypothesised that the mesenchymal nature of neuroblastoma cells is a reason, at least in part, for the aggressive and treatment resistant phenotype.
\end{abstract}

Methods: In order to validate our hypothesis, we used publicaly available RNA-Seq data, in vitro assays and xenograft mouse models.

Results: Using a combinatorial treatment of mesenchymal-to-epithelial inducers (curcumin or silibinin) with doxorubicin significantly increased the cell death in a panel of neuroblastoma cells in vitro. Follow up analysis in vivo, confirmed the therapeutic benefit of utilising the combination of curcumin with doxorubicin. The combinatorial therapy significantly reduced the tumor burden and increased the survival of mice implanted with high-risk neuroblastoma cells.

Cc) (C) The Author(s) 2020. Open Access This article is licensed under a Creative Commons Attribution 4.0 International License (https://creativecommons.org/licenses/by/4.0/), which permits unrestricted use, sharing, adaptation, distribution and reproduction in any medium or format, for any purpose, even commercially, as long as you give appropriate credit to the original author(s) and the source, provide a link to the Creative Commons license, and indicate if changes were made.

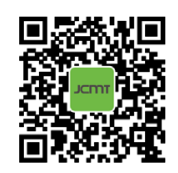


Conclusion: Taken together, this study shows the efficacy of using curcumin in combination with doxorubicin to improve the survival rate and has the potential to enhance the quality of life of neuroblastoma patients.

Keywords: Neuroblastoma, epithelial-to-mesenchymal transition, curcumin, silibinin, combinatorial therapy

\section{INTRODUCTION}

Neuroblastoma is the most common extracranial solid tumour that occurs in childhood ${ }^{[1]}$. It usually arises from the sympathetic nervous system and originates from the neuroepithelial cells of neural crest tissues $^{[2]}$. The clinical behaviour of this complex disease is highly diverse, ranging from a benign tumour mass with no symptoms to a progressive and fatal disease with resistance to current treatments ${ }^{[2,3]}$. This aggressive cancer is the most common cancer diagnosed during the first two years of human life ${ }^{[4]}$. The most important prognostic factor in neuroblastoma is the stage of the disease while the age of the patients remains an independent prognostic factor. Interestingly, infants less than 12 months with stages beyond 1, have significantly better disease-free survival rates than older children who are diagnosed with the same stage ${ }^{[5-8]}$. The histopathologic features of tumours are also classified as favourable or unfavourable depending on the differentiation of neuroblasts and Schwannian stroma content ${ }^{[9]}$. In addition, the presence of amplified transcription factor N-Myc in neuroblastoma patients (about 20\%) strongly correlates with poor prognosis and tumour dissemination. As amplification of $\mathrm{N}$-Myc has a profound effect on clinical outcome in neuroblastoma patients, N-Myc copy number has been used as a biomarker ${ }^{\left[10^{-12}\right]}$. The heterogeneity of neuroblastoma has resulted in decrease in the effectiveness of the therapeutic strategies over the past decades. However, tumours with favourable prognostic markers do not require as intense chemotherapy as the tumours with adverse factors. Hence, the Children's Oncology Group has developed a risk group stratification system in order to categorise the treatment strategies ${ }^{[13]}$. This system is mainly based on the stage of the disease, amplification status of N-Myc, DNA index and histopathology.

Even though the overall outcome of the neuroblastoma patients has improved recently, the survival rates of the children with high-risk neuroblastoma have not shown a substantive improvement ${ }^{[14,15]}$. Hence, there is a need for better therapeutic avenues to treat high-risk neuroblastoma ${ }^{[1,16,17]}$. Regardless of the efforts and current developments in treating high-risk patients, most of them relapse due to acquired drug resistance. Moreover, the survivors of high-risk neuroblastoma have manifested adverse effects to current therapeutics, which in turn has impaired their quality of life. Some of the uncovered effects from radiotherapy and surgery are damages to eyes, osteoporosis and various other musculoskeletal abnormalities ${ }^{[18,19]}$. Unfortunately, damages to renal tubes, chronic abnormalities in electrolytes, impaired sexual maturation, premature menopause and growth hormone deficiency can also occur due to long-term exposure to chemotherapy ${ }^{[20-25]}$. When considering all these factors, there is an urgent need of developing therapeutic strategies with natural compounds that increase the anti-cancer activity with lower side effects to enhance the quality of life of neuroblastoma patients.

Epithelial-to-mesenchymal transition (EMT) is a cellular process where epithelial cells lose their adhesion properties and turn mesenchymal. This highly plastic and dynamic shift towards the mesenchymal state is considered as EMT, wherein the expression of the adhesion proteins are downregulated so as to promote migration and invasion ${ }^{[26,2]}$. On the contrary, mesenchymal-epithelial transition (MET) is the reverse of EMT, wherein the expression of adhesion proteins are upregulated and the cells lose the migratory phenotype ${ }^{[28]}$. It is well established that EMT regulates cancer metastasis. Recent evidence suggests that EMT also regulates chemotherapeutic drug resistance in several cancer types. Human colorectal cancer (CRC) cell lines KM12L4 and HT29 displayed EMT because of oxaliplatin resistance by translocating $\beta$-Catenin to the nucleus ${ }^{[29]}$. Hepatocellular carcinoma cells resistant to 5-Fluorouracil (5-FU) also showed 
induction of EMT with the upregulation of Twist and the down regulation of E-Cadherin ${ }^{[30]}$. Similarly, activation of Snail in CRC cell lines led to increased motility and invasiveness with increased resistance to 5- $\mathrm{FU}^{[31]}$. Collectively, these data suggest that EMT plays a role in chemoresistance. Neuroblastoma cells, due to their origin, are more mesenchymal and it is highly likely that the inherent resistance to treatment could be partly attributed to EMT. It is unclear whether the utility of MET inducers along with standard chemotherapeutic drugs could increase the sensitivity of the neuroblastoma cells.

Curcumin and silibinin are natural components that have exhibited anti-cancer activities and can induce MET in many adult cancers with less or no toxicity ${ }^{[32,33]}$. These natural active ingredients have been implicated in suppressing various growth and pro-invasive signalling pathways as well as inducing cell death in a variety of cancer cells ${ }^{[34-36]}$. In non-N-Myc amplified SH-SY-5Y neuroblastoma cells, curcumin was shown to induce cell death in vitro ${ }^{[37]}$. However, in vivo studies that highlight the therapeutic potential of curcumin and silibinin in treating high-risk neuroblastoma cells are currently lacking. In addition, the utility of these natural compounds in combinatorial therapy with doxorubicin in vivo has not been examined. In this study, we examined the combinatorial effect of curcumin or silibinin in sensitising neuroblastoma cells to the chemotherapeutic drug doxorubicin both in vitro and in vivo.

\section{METHODS}

\section{RNA-Seq analysis}

The RNA-Seq data for NBL and CRC cell lines and tissues were downloaded from published literature ${ }^{[38]}$. The mRNA expression ( $\log _{2}$ RPKM values) of genes categorised as epithelial and mesenchymal were plotted using MATLAB. Genes (315) classified as epithelial and mesenchymal were downloaded from published literature $^{[39]}$. Statistical analysis to calculate the significance was performed using the Pearson's chi-square test. $P$-values less than 0.05 were considered statistically significant.

\section{Cell culture}

The neuroblastoma cell lines SK-N-BE2, SH-SY5Y and SK-N-AS were cultured in $150 \mathrm{~cm}^{2}$ tissue culture flasks (BD Falcon ${ }^{\mathrm{TM}}$ ) in Dulbecco's Modified Eagle Medium (DMEM) (GIBCO, Life Technologies) medium supplemented with $10 \%(\mathrm{v} / \mathrm{v})$ fetal calf serum (GIBCO, Life Technologies) and 100 units $/ \mathrm{mL}$ of penicillinstreptomycin (GIBCO, Life Technologies). IMR32 neuroblastoma cells were cultured in Minimum Essential Medium (GIBCO, Life Technologies) medium. The cells were incubated at $37^{\circ} \mathrm{C}$ with $5 \% \mathrm{CO}_{2}$. SK-N-BE2 $\left(\mathrm{CRL}-2271^{\mathrm{TM}}\right.$ ) and IMR32 (CCL-127 ${ }^{\mathrm{TM}}$ ) cells were purchased from ATCC ${ }^{\circ}$, while SH-SY5Y and SK-N-AS cells were kindly gifted by Dr Julie Atkin.

\section{Whole cell lysate preparation}

Neuroblastoma cells were treated with $10 \mu \mathrm{M}$ curcumin and $100 \mu \mathrm{M}$ silibinin for 24 and $48 \mathrm{~h}$ prior to preparation of cell lysates. Cells were lysed as described previously ${ }^{[40]}$ using $4 \times$ sodium dodecyl sulfate (SDS) loading dye [2\% (w/v) SDS, $125 \mathrm{mM}$ Tris- $\mathrm{HCl} \mathrm{pH}$ 7.4, 12.5\% (v/v) glycerol and 0.02\% (w/v) bromophenol blue]. Briefly, loading dye $(1.5 \mathrm{~mL}$ ) was added to culture dishes and evenly spread using the cell lifter (Fisher Biotec). The lysate was then collected in thick wall polyallomer tubes (Beckman Coulter) and centrifuged at $100,000 \mathrm{~g}$ for $1 \mathrm{~h}$ (TLA 100.2, Beckman). Supernatant was collected and stored at $-80{ }^{\circ} \mathrm{C}$ for further analysis.

\section{SDS-PAGE and Western blotting}

Equal amount of protein samples was prepared in $4 \times$ SDS loading buffer with $100 \mathrm{mM}$ DTT (Astral). Samples were then denatured by heating at $95{ }^{\circ} \mathrm{C}$ for $2 \mathrm{~min}$ and were run on a NuPAGE $4 \%-12 \%$ Bis-Tris

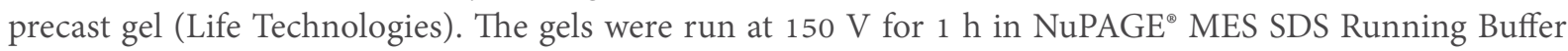
(Life Technologies). Proteins were transferred on to nitrocellulose membrane using iBlot dry blotting system 
(Invitrogen $^{\mathrm{TM}}$ ) at $20 \mathrm{~V}$ for $7 \mathrm{~min}$. The membrane was incubated with blocking solution containing $5 \%(\mathrm{w} / \mathrm{v})$ skim milk in Tris-buffered saline with $0.05 \%$ Tween 20 (TTBS) [100 mM Tris- $\mathrm{HCl}$ pH 7.5, $150 \mathrm{mM} \mathrm{NaCl}$ and $0.05 \%(\mathrm{v} / \mathrm{v}$ ) Tween 20] for $45 \mathrm{~min}$. The membrane was washed three times with TTBS (10 min each) and probed with the relevant primary antibody overnight at $4{ }^{\circ} \mathrm{C}$. The membrane was again washed with TTBS over $30 \mathrm{~min}$. Subsequently, the blot was probed with appropriate IRDye (LI-COR ${ }^{\circledR}$ ) or peroxidase $\left(\right.$ Sigma-Aldrich ${ }^{\circ}$ ) conjugated secondary antibody for $1 \mathrm{~h}$ at room temperature. The blot was then washed three times with TTBS over $30 \mathrm{~min}$. For the visualisation of the protein bands probed with IRDye (LI-COR ${ }^{\star}$ ), ODYSSEY CLX (LI-COR ${ }^{\circ}$ ) machine was used.

\section{Cell death assay}

Cells $\left(5 \times 10^{3}\right.$ per well $)$ were seeded in a 24 -well plate in $500 \mu \mathrm{L}$ DMEM medium and allowed to adhere for $48 \mathrm{~h}$ at $37^{\circ} \mathrm{C}$ in the presence of $5 \% \mathrm{CO}_{2}$. Cells were then treated with or without doxorubicin $(1 \mu \mathrm{M})$ and incubated for $48 \mathrm{~h}$. For combinational treatment studies, curcumin $(10 \mu \mathrm{M})$ or silibinin $(100 \mu \mathrm{M})$ treatment was performed $24 \mathrm{~h}$ before the addition of doxorubicin (pre-treatment) as well as on the same day of doxorubicin treatment (combinational). After $48 \mathrm{~h}$ of cancer therapeutic drug treatment, cells were scraped and resuspended. Supernatant $(300 \mu \mathrm{L})$ was then transferred in to a 96 -well plate and spun at $300 \mathrm{~g}$ for $5 \mathrm{~min}$ before discarding the supernatant. The remaining pellet was then resuspended with 200 $\mu \mathrm{L}$ of propidium iodide (PI) buffer [0.1\% (w/v) TritonX 100 and $50 \mu \mathrm{g} / \mathrm{mL}$ Propidium iodide (Sigma Life Science ${ }^{\otimes}$ and was incubated overnight at $4{ }^{\circ} \mathrm{C}$. For this, $2 \times 10^{4}$ cells were used in the analysis, Results from fluorescence activated cell sorting CANTO II (BD Biosciences) were then analysed using FlowJo (TreeStar).

\section{Establishment of tumour xenografts}

SK-N-BE2 cells $\left(5 \times 10^{6}\right)$ were subcutaneously injected to athymic Balb/c nude female mice ( 8 weeks old). The cells were suspended in Matrigel before the injections. After formation of tumours, the mice were injected intraperitoneally (i.p.) with dimethyl sulfoxide (DMSO) (control), curcumin (40 mg/kg), doxorubicin (5 mg/ $\mathrm{kg}$ ) and combinational treatment of doxorubicin and curcumin three times a week. Tumour size and the weight of the mice were measured daily. The tumour volume was calculated according to the formula $1 / 2\left(\mathrm{~W}^{2} \times \mathrm{L}\right)$. According to the Australian code of practice for the care and use of animals for scientific purposes and La Trobe Ethics Committee guidelines (AEC 14-15), mice were sacrificed when the tumour size reached $1500 \mathrm{~mm}^{3}$.

\section{Statistical analysis}

Statistical significance of experiments was analysed by student $t$-test and $P$ values less than 0.05 were considered to be statistically significant. CI (Combination index) was calculated using Chou-Talalay $\operatorname{method~}^{[41]}$. A violin plot was generated using MATLAB and the $P$ value of the violin plot was also calculated using MATLAB ${ }^{[42]}$.

\section{RESULTS}

\section{Neuroblastoma cells exhibit mesenchymal signature}

Prior to commencement of the experiments, publicly available RNA-Seq data for neuroblastoma tissues and cells were queried for the expression of EMT genes to examine the hypothesis of whether the neuroblastoma cells are mesenchymal. To validate the expression of epithelial and mesenchymal genes, publicly available RNA-Seq data for neuroblastoma cell lines and tissues were examined. In total, 315 genes implicated in EMT were retrieved from the public literature ${ }^{[43]}$ and the expression profile of these genes were plotted in a panel of neuroblastoma cell lines and tissues [Figure 1]. Interestingly, agreeing with our hypothesis, neuroblastoma cell lines $(n=8)$ and tissues $(n=157)$ exhibited a high mesenchymal and low epithelial gene expression. These results suggest that neuroblastoma cells are mesenchymal and hence could contribute to the aggressive phenotype. 


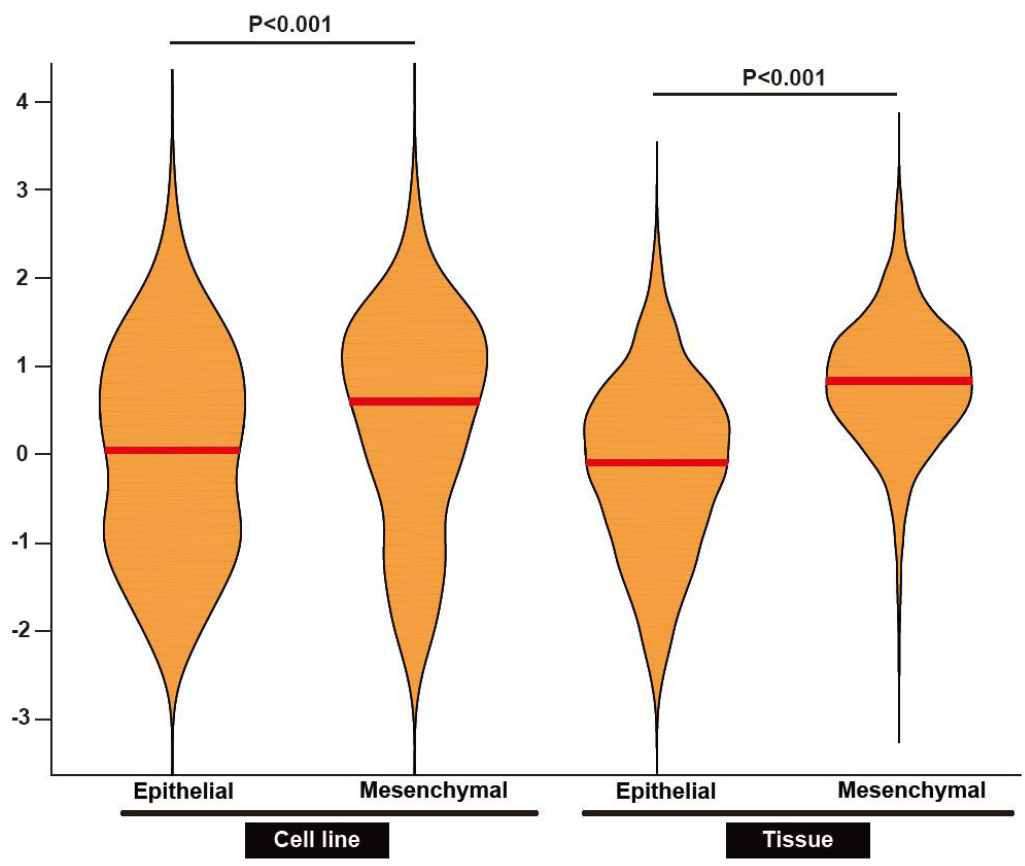

Figure 1. Neuroblastoma cells and tissues have a high mesenchymal gene signature. Violin plot representation of epithelial and mesenchymal gene expression in neuroblastoma cell lines $(n=8)$ and tissues $(n=157)$ is depicted. The red line represents the median. $P$ value was determined by Mann-Whitney test

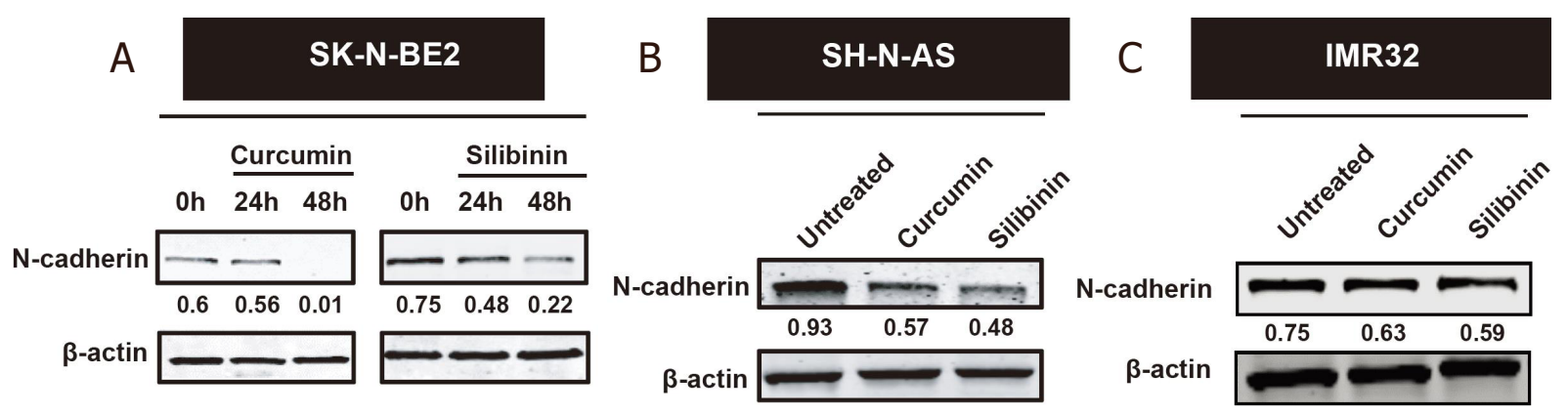

Figure 2. Curcumin and silibinin reduced the expression of the mesenchymal marker $\mathrm{N}$-Cadherin. $\mathrm{A}$ : Western blot analysis for $\mathrm{N}$-Cadherin in SK-N-BE2 cells; B: Western blot analysis for N-Cadherin in SH-N-AS cells; C: Western blot analysis for N-Cadherin in IMR32 cells. Drug concentration: $10 \mu \mathrm{M}$ curcumin or $100 \mu \mathrm{M}$ silibinin. $\beta$-actin was used the loading control. The $\mathrm{N}$-cadherin band intensities are normalised to respective band intensities of $\beta$-actin

\section{Curcumin and silibinin reduce the expression of mesenchymal marker $\mathrm{N}$-Cadherin}

If the mesenchymal nature of neuroblastoma cells account for the treatment resistance, induction of an epithelial phenotype by MET inducers could sensitise the neuroblastoma cells to doxorubicin. To test this hypothesis, MET inducers such as curcumin and silibinin were utilised in this study. It has been previously established that curcumin and silibinin can reverse EMT in certain cancer types ${ }^{[44,45]}$. Consistent with the literature, treatment of the cancer cells with curcumin and silibinin reduced the expression of mesenchymal marker N-Cadherin [Figure $2 \mathrm{~A}-\mathrm{C}]^{[46,47]}$. N-cadherin is a well-established mesenchymal marker that promotes cell motility and migration ${ }^{[48]}$. The reduction of $\mathrm{N}$-Cadherin levels was only observed at $10 \mu \mathrm{M}$ for curcumin and $100 \mu \mathrm{M}$ for silibinin. Epithelial markers E-Cadherin and Keratin 18 could not be detected in the neuroblastoma cells with or without the MET inducers. Similarly, the expression of another mesenchymal marker, Vimentin, did not change in the neuroblastoma cells treated with or without curcumin or silibinin (data not shown). 


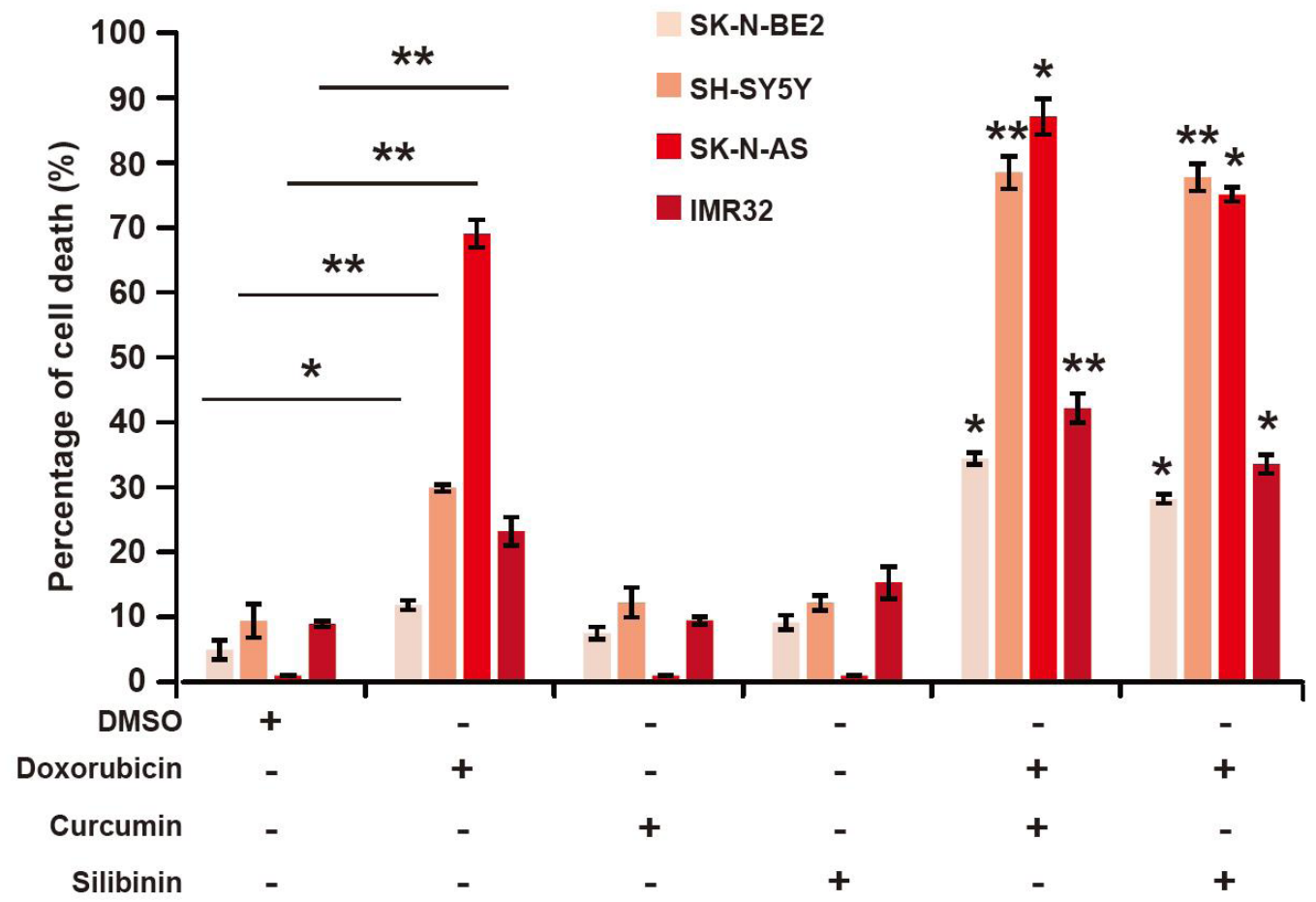

Figure 3. Curcumin and silibinin increases the sensitivity of neuroblastoma cells to doxorubicin. FACS cell death assay on a panel of neuroblastoma cells treated with $10 \mu \mathrm{M}$ curcumin or $100 \mu \mathrm{M}$ silibinin in the presence of $1 \mu \mathrm{M}$ doxorubicin $(n=3)$. Data are presented as mean $\pm \mathrm{SEM},{ }^{\star} P<0.05 ;{ }^{\star \star} P<0.01$ as determined by Student's $t$-test. Significance of the percentage of cell death in combinational treatments was calculated in comparison to respective doxorubicin only treatments. DMSO: dimethyl sulfoxide; FACS: fluorescence activated cell sorting

\section{Combinatorial treatment of curcumin or silibinin with doxorubicin sensitises neuroblastoma cells}

Curcumin and silibinin are natural compounds that have many anti-cancer properties including induction of $\mathrm{MET}^{[34-36]}$. As neuroblastoma cells, especially high-risk ones, are aggressive and resistant to treatment, the combinatorial effect of curcumin or silibinin with doxorubicin was examined to understand their therapeutic potential. A panel of four neuroblastoma cells, namely SH-SY-5Y, SK-N-AS, SK-N-BE2 and IMR32, was selected for the in vitro analysis. Among these neuroblastoma cells, SH-Y-5Y and SK-NAS cells are low-risk and do not contain N-Myc amplification ${ }^{[49]}$. On the contrary, SK-N-BE2 and IMR32 cells are high-risk neuroblastoma cell models with $\mathrm{N}$-Myc amplification (>0 copies) ${ }^{[49]}$. Consistent with the literature, treatment of the low-risk neuroblastoma cells (SH-SY-5Y and SK-N-AS) with the chemotherapeutic agent doxorubicin $(1 \mu \mathrm{M})$ induced significant cell death [Figure 3]. Whilst the basal cell death for SK-N-AS cells was about $1 \%$, incubation with doxorubicin induced nearly $70 \%$ cell death, an increase by 70 -fold. Similarly, SH-SY-5Y cells exhibited more than three-fold cell death (30\%) upon doxorubicin treatment. However, the high-risk neuroblastoma cells (SK-N-BE2 and IMR32) showed lesser percentage of cell death ( $11.8 \%$ and $23 \%$, respectively) when incubated with the chemotherapeutic agent doxorubicin $(1 \mu \mathrm{M})$. This relates to a 2.3- and 2.6-fold increase in cell death in SK-N-BE2 and IMR32 cells, respectively.

Next, the combinatorial effect of curcumin or silibinin with doxorubicin was evaluated in the panel of neuroblastoma cells. As shown in Figure 3, neither curcumin $(10 \mu \mathrm{M})$ nor silibinin $(100 \mu \mathrm{M})$ induced significant cell death in any of the neuroblastoma cells. The concentration for curcumin and silibinin was chosen as they reduced the expression of $\mathrm{N}$-Cadherin in neuroblastoma cells. When performing the 
A

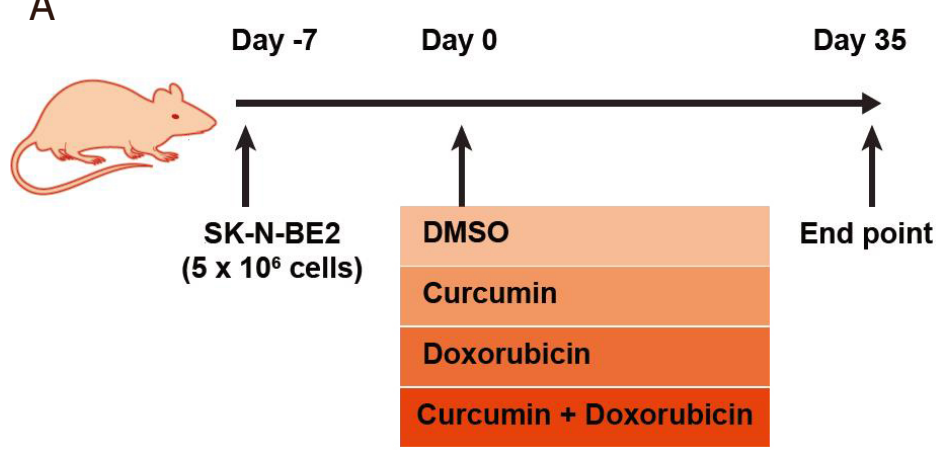

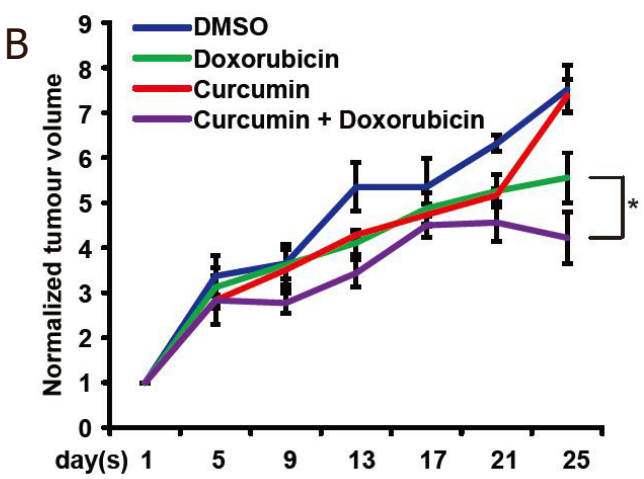

Figure 4. Combinatorial therapy reduces the tumour burden. A: schematic representation of in vivo work to examine the efficacy of combinatorial therapy on neuroblastoma tumour burden. B: relative tumour volume across a period in the presence of curcumin and/or doxorubicin $(n=3)$. Data are presented as mean \pm SEM, ${ }^{\star} P<0.05$ as determined by Student's $t$-test. DMSO: dimethyl sulfoxide

combinational treatments, the cells were treated with curcumin and silibinin $24 \mathrm{~h}$ prior to doxorubicin treatment to allow the induction of MET. Nevertheless, combination of curcumin with doxorubicin induced significant cell death in both the low- and high-risk neuroblastoma cells. Compared to the doxorubicin alone treatment, a 2.9-, 2.6-, 1.3- and 1.8-fold increase in cell death was observed in SK-N-BE2, SH-SY$5 Y$, SK-N-AS and IMR32 cells, respectively. Moreover, the Combination index (CI) values obtained for the treatments were $<0.1$, indicating a synergism. The CI values were 0.56 and 0.5 for SK-N-BE2 and SH-SY-5Y cells, respectively. Consistent with these results, combinatorial treatment of silibinin and doxorubicin also induced significant cell death, compared to doxorubicin alone, in the panel of neuroblastoma cells. Taken together, these data suggest that curcumin and silibinin can increase cell death induced by doxorubicin in both low- and high-risk neuroblastoma cells. The data also suggested that curcumin along with doxorubicin was more effective in inducing cell death in the neuroblastoma cells.

\section{Combinational treatment reduced the tumour burden and increased the survival of mice implanted with neuroblastoma}

Several studies have examined the effect of curcumin or silibinin on inducing cell death in neuroblastoma cells ${ }^{[37]}$. However, the therapeutic potential has not been examined in vivo. Furthermore, it is unclear whether a combinatorial treatment that increases cell death in neuroblastoma cells also works in vivo. Hence, to validate the effect of combinatorial treatment in vivo, nude mice were injected with the highrisk SK-N-BE2 neuroblastoma cells $\left(5 \times 10^{6}\right)$ subcutaneously. N-Myc amplified SK-N-BE2 cells are more proliferative and resistant to doxorubicin treatment [Figure 3] than the other neuroblastoma cells used in this study, hence was chosen as a model cell line. After formation of tumours, the mice were administered (i.p.) with DMSO (control), doxorubicin, curcumin or a combination of doxorubicin and curcumin twice per week [Figure 4A]. Here, curcumin was chosen as the curcumin treatment had more effect on $\mathrm{N}$-cadherin expression level [Figure 2A] and cell death [Figure 3] than silibinin. The tumour volume was monitored daily in the control and treatment groups. Tumour volume was the highest in mice that received DMSO or curcumin alone [Figure $4 \mathrm{~B}$ ]. Consistent with the in vitro data and literature, mice that were treated with doxorubicin alone had a significant decrease in the tumour volume. Encouragingly, the tumour volume in mice treated with both doxorubicin and curcumin was significantly smaller compared to those receiving only doxorubicin. There were no visible side effects from any of the treatments and no change in body weight of the mice was observed [Figure 5A]. Importantly, mice that received combinational treatment exhibited a higher survival rate [Figure 5B]. Taken together, these results suggest that treatment of curcumin in combination with a chemotherapeutic drug may be a viable strategy to treat neuroblastoma patients, most importantly high-risk neuroblastoma patients with $\mathrm{N}-\mathrm{Myc}$ amplification. 
A

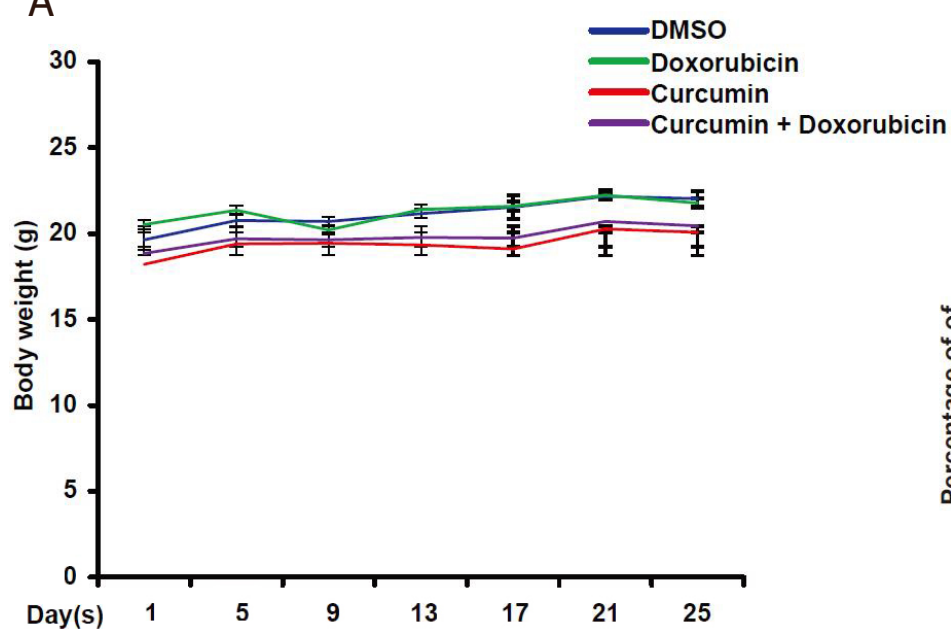

B

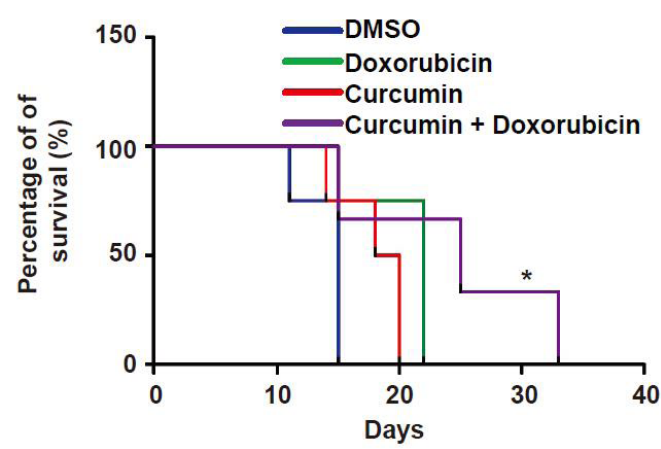

Figure 5. Combinatorial therapy increases the survival of mice implanted with neuroblastoma cells. A: graphical representation of body weight of mice over the period in the presence or absence of curcumin and doxorubicin $(n=3)$. Treatment with curcumin and doxorubicin does not impart visible side effects in mice. B: Kaplan-Meier analysis of the survival rate of mice bearing neuroblastoma tumour undergoing treatment. Combinatorial treatment significantly enhanced the survival of mice $\left({ }^{\star} P<0.05\right)$. DMSO: dimethyl sulfoxide

\section{DISCUSSION}

Neuroblastoma is the most common extracranial solid tumour in children under the age of five. Depending on risk factors, neuroblastoma can be divided in to low- and high-risk ${ }^{[50]}$. Even though the survival rates of low-risk neuroblastoma have improved significantly, the survival rates of high-risk neuroblastoma have remained poor ${ }^{[51]}$. Among the risk factors, amplification of the oncogene N-Myc is detected in about $20 \%$ of neuroblastoma patients and considered high-risk ${ }^{[52]}$. Hence, therapeutic strategies to manage high-risk $\mathrm{N}-\mathrm{Myc}$ amplified neuroblastoma cells is needed.

Curcumin and silibinin have shown anticancer properties by modulating several signalling pathways ${ }^{[34,36,53-55]}$. More importantly, it is documented that curcumin and silibinin have the ability to repress proteins that are involved in EMT and metastasis ${ }^{[45,47,56]}$. We sought to elucidate the role of curcumin or silibinin in combination with doxorubicin.

First, the results from publicly available RNA-Seq analysis suggest that the mesenchymal-like phenotype exhibited by neuroblastoma cells could be one of the potential reasons for the aggressiveness. In the current study, we targeted the utility of curcumin or silibinin in sensitising neuroblastoma cells to doxorubicin. Combinatorial therapy of curcumin and doxorubicin sensitised the highly aggressive neuroblastoma cells both in vitro and in vivo. Here, we utilised four neuroblastoma cell lines, among which SK-N-BE2 and IMR32 possess N-Myc amplification and hence are categorised as high-risk aggressive neuroblastoma. $\mathrm{N}-\mathrm{Myc}$ is not amplified in SH-SY-5Y and SK-N-AS cells, which were used to identify the usage of combinational therapy in a wider range of neuroblastoma cells.

Agreeing with the previous literature, curcumin and silibinin reduced the expression of the mesenchymal marker N-Cadherin and induced $\mathrm{MET}^{[37]}$. However, the combinatorial effect with doxorubicin can also be attributed to other anti-cancer activities of these MET inducers, such as inhibition of p53, pAKt and STAT3 signalling pathway ${ }^{[34,53,57]}$. Moreover, recent findings also suggest curcumin and silibinin as agents that can inhibit the cancer stem cells growth ${ }^{[58,59]}$. Nevertheless, based on these results, curcumin and silibinin are interesting candidates for combination with standard chemotherapeutic drugs including doxorubicin for 
neuroblastoma treatment. As mentioned above, despite aggressive therapy, the overall survival for high-risk neuroblastoma patients is $<50 \%$ at five years ${ }^{[60]}$. In fact, the survival rate of relapsed stage 4 neuroblastoma patients as per the International Neuroblastoma Risk Group database between 1990 and 2002 is $8 \%{ }^{[61]}$. Alarmingly, the survival rate drops below $4 \%$ for N-Myc amplified neuroblastoma patients.

Hence, the findings from this study have clear potential therapeutic benefits to increase the survival of the high-risk neuroblastoma patients. Importantly, as curcumin and silibinin have been shown to be safe and well-tolerated in randomised clinical trials ${ }^{[6-67]}$, they can be readily utilised for neuroblastoma therapy.

\section{DECLARATIONS}

\section{Authors' contributions}

Conceived and directed the entire project: Mathivanan S

Performed the experiments: Fonseka P, Angela DG, Gangoda L

Performed bioinformatics analysis: Pathan $\mathrm{M}$

Prepared the figures, drafted and finalized the manuscript with inputs from other authors: Fonseka P, Mathivanan S

Read and approved the manuscript: Fonseka P, Gangoda L, Pathan M, Angela DG, Mathivanan S

\section{Availability of data and materials}

Not applicable.

\section{Financial support and sponsorship}

Suresh Mathivanan is supported by ANZ Trustees and Ramaciotti Establishment Grant. Suresh Mathivanan is supported by Australian Research Council Future Fellowship (FT180100333) but the project was not funded by the basic science fellowship. Angela Di Giannatale is supported by a Grant from the Italian Ministry of Health (GR-2016-02364088). The funders had no role in study design, data collection and analysis, decision to publish, or preparation of the manuscript.

\section{Conflicts of interest}

All authors declared that there are no conflicts of interest.

\section{Ethical approval and consent to participate}

Animal study was conducted according to Australian code of practice for the care and use of animals for scientific purposes and La Trobe Ethics Committee guidelines (AEC 14-15).

\section{Consent for publication}

Not applicable.

\section{Copyright}

(c) The Author(s) 2020.

\section{REFERENCES}

1. Maris JM, Hogarty MD, Bagatell R, Cohn SL. Neuroblastoma. Lancet 2007;369:2106-20.

2. Maris JM. Recent advances in neuroblastoma. N Engl J Med 2010;362:2202-11.

3. Gangoda L, Keerthikumar S, Fonseka P, Edgington LE, Ang CS, et al. Inhibition of cathepsin proteases attenuates migration and sensitizes aggressive N-Myc amplified human neuroblastoma cells to doxorubicin. Oncotarget 2015;6:11175-90.

4. London WB, Castleberry RP, Matthay KK, Look AT, Seeger RC, et al. Evidence for an age cutoff greater than 365 days for neuroblastoma risk group stratification in the Children's Oncology Group. J Clin Oncol 2005;23:6459-65.

5. Evans AE, D’Angio GJ, Propert K, Anderson J, Hann HWL. Prognostic factors in neuroblastoma. Cancer 1987;59:1853-9. 
6. Evans AE, D'Angio GJ, Randolph J. A proposed staging for children with neuroblastoma. Children's cancer study group A. Cancer 1971;27:374-8.

7. Cheung NKV, Zhang J, Lu C, Parker M, Bahrami A, et al. Association of age at diagnosis and genetic mutations in patients with neuroblastoma. JAMA 2012;307:1062-71.

8. Schilling FH, Spix C, Berthold F, Erttmann R, Fehse N, et al. Neuroblastoma screening at one year of age. N Engl J Med 2002;346:1047-53.

9. Brodeur GM, Pritchard J, Berthold F, Carlsen NL, Castel V, et al. Revisions of the international criteria for neuroblastoma diagnosis, staging, and response to treatment. J Clin Oncol 1993;11:1466-77.

10. Seeger RC, Brodeur GM, Sather H, Dalton A, Siegel SE, et al. Association of Multiple Copies of the N-myc Oncogene with Rapid Progression of Neuroblastomas. N Engl J Med 1985;313:1111-6.

11. Oppedal BR, Oien O, Jahnsen T, Brandtzaeg P. N-myc amplification in neuroblastomas: histopathological, DNA ploidy, and clinical variables. J Clin Pathol 1989;42:1148-52.

12. Rubie H, Hartmann O, Michon J, Frappaz D, Coze C, et al. N-Myc gene amplification is a major prognostic factor in localized neuroblastoma: results of the French NBL 90 study. Neuroblastoma Study Group of the Société Francaise d'Oncologie Pédiatrique. J Clin Oncol 1997;15:1171-82.

13. Bowman LC, Castleberry RP, Cantor A, Joshi V, Cohn SL, et al. Genetic staging of unresectable or metastatic neuroblastomain infants: a pediatric oncology group study. J Natl Cancer Inst 1997;89:373-80.

14. Chang PCY, Wang NL, Liu HC, Liang DC, Yeh TC, et al. Low-stage pediatric neuroblastoma: a 20-year single institution review. J Cancer Res Pract 2018;5:9-12.

15. Sharma R, Mer J, Lion A, Vik TA. Clinical presentation, evaluation, and management of neuroblastoma. Pediatr Rev 2018;39:194-203.

16. Matthay KK, Villablanca JG, Seeger RC, Stram DO, Harris RE, et al. Treatment of high-risk neuroblastoma with intensive chemotherapy, radiotherapy, autologous bone marrow transplantation, and 13-cis-retinoic acid. N Engl J Med 1999;341:1165-73.

17. Luksch R, Castellani MR, Collini P, De Bernardi B, Conte M, et al. Neuroblastoma (Peripheral neuroblastic tumours). Crit Rev Oncol Hematol 2016;107:163-81.

18. Mertens AC, Yasui Y, Neglia JP, Potter JD, Nesbit ME, et al. Late mortality experience in five-year survivors of childhood and adolescent cancer: the childhood cancer survivor study. J Clin Oncol 2001;19:3163-72.

19. Whelan KF, Stratton K, Kawashima T, Waterbor JW, Castleberry RP, et al. Ocular late effects in childhood and adolescent cancer survivors: a report from the childhood cancer survivor study. Pediatr Blood Cancer 2010;54:103-9.

20. Friedman DL, Meadows AT. Late effects of childhood cancer therapy. Pediatr Clin North Am 2002;49:1083-106.

21. Friedman DL, Freyer DR, Levitt GA. Models of care for survivors of childhood cancer. Pediatr Blood Cancer 2006;46:159-68.

22. Nandagopal R, Laverdiere C, Mulrooney D, Hudson MM, Meacham L. Endocrine late effects of childhood cancer therapy: a report from the Children's Oncology Group. Horm Res 2008;69:65-74.

23. Dickerman JD. The late effects of childhood cancer therapy. Pediatrics 2007;119:554-68.

24. Rose SR, Horne VE, Howell J, Lawson SA, Rutter MM, et al. Late endocrine effects of childhood cancer. Nat Rev Endocrinol 2016;12:319-36

25. Perwein T, Lackner H, Sovinz P, Benesch M, Schmidt S, et al. Survival and late effects in children with stage 4 neuroblastoma. Pediatr Blood Cancer 2011;57:629-35.

26. Son H, Moon A. Epithelial-mesenchymal transition and cell invasion. Toxicol Res 2010;26:245-52.

27. Yilmaz M, Christofori G. EMT, the cytoskeleton, and cancer cell invasion. Cancer Metastasis Rev 2009;28:15-33.

28. Jolly MK, Ware KE, Gilja S, Somarelli JA, Levine H. EMT and MET: necessary or permissive for metastasis? Mol Oncol 2017;11:755-69.

29. Yang AD, Fan F, Camp ER, van Buren G, Liu W, et al. Chronic oxaliplatin resistance induces epithelial-to-mesenchymal transition in colorectal cancer cell lines. Clin Cancer Res 2006;12:4147-53.

30. Uchibori K, Kasamatsu A, Sunaga M, Yokota S, Sakurada T, et al. Establishment and characterization of two 5-fluorouracil-resistant hepatocellular carcinoma cell lines. Int J Oncol 2012;40:1005-10.

31. Hoshino H, Miyoshi N, Nagai K, Tomimaru Y, Nagano H, et al. Epithelial-mesenchymal transition with expression of SNAI1-induced chemoresistance in colorectal cancer. Biochem Biophys Res Commun 2009;390:1061-5.

32. Tomeh MA, Hadianamrei R, Zhao X. A review of curcumin and its derivatives as anticancer agents. Int J Mol Sci 2019;20:1033.

33. Raina K, Kumar S, Dhar D, Agarwal R. Silibinin and colorectal cancer chemoprevention: a comprehensive review on mechanisms and efficacy. J Biomed Res 2016;30:452-65.

34. Bosch-Barrera J, Queralt B, Menendez JA. Targeting STAT3 with silibinin to improve cancer therapeutics. Cancer Treat Rev 2017;58:61-9.

35. Singh RP, Agarwal R. Mechanisms of action of novel agents for prostate cancer chemoprevention. Endocr Relat Cancer 2006;13:751-78.

36. Sidhar H, Giri RK. Induction of Bex genes by curcumin is associated with apoptosis and activation of p53 in N2a neuroblastoma cells. Sci Rep 2017;7:41420.

37. Namkaew J, Jaroonwitchawan T, Rujanapun N, Saelee J, Noisa P. Combined effects of curcumin and doxorubicin on cell death and cell migration of SH-SY5Y human neuroblastoma cells. In Vitro Cell Dev Biol Anim 2018;54:629-39.

38. Klijn C, Durinck S, Stawiski EW, Haverty PM, Jiang ZS, et al. A comprehensive transcriptional portrait of human cancer cell lines. Nat Biotechnol 2015;33:306-12.

39. Tan TZ, Miow QH, Miki Y, Noda T, Mori S, et al. Epithelial-mesenchymal transition spectrum quantification and its efficacy in deciphering survival and drug responses of cancer patients. EMBO Mol Med 2014;6:1279-93.

40. Mathivanan S, Ji H, Tauro BJ, Chen YS, Simpson RJ. Identifying mutated proteins secreted by colon cancer cell lines using mass spectrometry. J Proteomics 2012;76:141-9. 
41. Chou TC. Drug combination studies and their synergy quantification using the Chou-Talalay method. Cancer Res 2010;70:440-6.

42. Hoffmann H. violin. m-Simple violin plot using matlab default kernel density estimation. Katzenburgweg, Germany: INRES (University of Bonn) 2015.

43. Tan TZ, Miow QH, Miki Y, Noda T, Mori S, et al. Epithelial-mesenchymal transition spectrum quantification and its efficacy in deciphering survival and drug responses of cancer patients. EMBO Mol Med 2014;6:1279-93.

44. Liang Z, Lu L, Mao J, Li X, Qian H, et al. Curcumin reversed chronic tobacco smoke exposure induced urocystic EMT and acquisition of cancer stem cells properties via Wnt/beta-catenin. Cell Death Dis 2017;8:e3066.

45. Li F, Sun Y, Jia J, Yang C, Tang X, et al. Silibinin attenuates TGFbetalinduced migration and invasion via EMT suppression and is associated with COX2 downregulation in bladder transitional cell carcinoma. Oncol Rep 2018;40:3543-50.

46. Cao L, Xiao X, Lei J, Duan W, Ma Q, et al. Curcumin inhibits hypoxia-induced epithelialmesenchymal transition in pancreatic cancer cells via suppression of the hedgehog signaling pathway. Oncol Rep 2016;35:3728-34.

47. Kim JS, Han NK, Kim SH, Lee HJ. Silibinin attenuates radiation-induced intestinal fibrosis and reverses epithelial-to-mesenchymal transition. Oncotarget 2017;8:69386-97.

48. Nakajima S, Doi R, Toyoda E, Tsuji S, Wada M, et al. N-cadherin expression and epithelial-mesenchymal transition in pancreatic carcinoma. Clin Cancer Res 2004;10:4125-33.

49. Veas-Perez de Tudela M, Delgado-Esteban M, Cuende J, Bolanos JP, Almeida A. Human neuroblastoma cells with MYCN amplification are selectively resistant to oxidative stress by transcriptionally up-regulating glutamate cysteine ligase. J Neurochem 2010;113:819-25.

50. Brodeur GM. Neuroblastoma: biological insights into a clinical enigma. Nat Rev Cancer 2003;3:203.

51. Smith V, Foster J. High-risk neuroblastoma treatment review. Children (Basel) 2018;5.

52. Kaczowka P, Wieczorek A, Czogala M, Ksiazek T, Szewczyk K, et al. The role of N-Myc gene amplification in neuroblastoma childhood tumour - single-centre experience. Contemp Oncol (Pozn) 2018;22:223-8.

53. Picone P, Nuzzo D, Caruana L, Messina E, Scafidi V, et al. Curcumin induces apoptosis in human neuroblastoma cells via inhibition of AKT and Foxo3a nuclear translocation. Free Radic Res 2014;48:1397-408.

54. Aggarwal BB, Harikumar KB. Potential therapeutic effects of curcumin, the anti-inflammatory agent, against neurodegenerative, cardiovascular, pulmonary, metabolic, autoimmune and neoplastic diseases. Int J Biochem Cell Biol 2009;41:40-59.

55. Deep G, Agarwal R. Anti-metastatic efficacy of silibinin: molecular mechanisms and therapeutic potential against cancer. Cancer Metastasis Rev 2010;29:447-63.

56. Wang Q, Qu C, Xie F, Chen L, Liu L, et al. Curcumin suppresses epithelial-to-mesenchymal transition and metastasis of pancreatic cancer cells by inhibiting cancer-associated fibroblasts. Am J Cancer Res 2017;7:125-33.

57. Ramasamy TS, Ayob AZ, Myint HH, Thiagarajah S, Amini F. Targeting colorectal cancer stem cells using curcumin and curcumin analogues: insights into the mechanism of the therapeutic efficacy. Cancer Cell Int 2015;15:96.

58. Kumar S, Raina K, Agarwal C, Agarwal R. Silibinin strongly inhibits the growth kinetics of colon cancer stem cell-enriched spheroids by modulating interleukin 4/6-mediated survival signals. Oncotarget 2014;5:4972-89.

59. Zang S, Liu T, Shi J, Qiao L. Curcumin: a promising agent targeting cancer stem cells. Anticancer Agents Med Chem 2014;14:787-92.

60. Basta NO, Halliday GC, Makin G, Birch J, Feltbower R, et al. Factors associated with recurrence and survival length following relapse in patients with neuroblastoma. Br J Cancer 2016;115:1048-57.

61. London WB, Castel V, Monclair T, Ambros PF, Pearson AD, et al. Clinical and biologic features predictive of survival after relapse of neuroblastoma: a report from the International Neuroblastoma Risk Group project. J Clin Oncol 2011;29:3286-92.

62. James MI, Iwuji C, Irving G, Karmokar A, Higgins JA, et al. Curcumin inhibits cancer stem cell phenotypes in ex vivo models of colorectal liver metastases, and is clinically safe and tolerable in combination with FOLFOX chemotherapy. Cancer Lett 2015;364:135-41.

63. Irving GR, Iwuji CO, Morgan B, Berry DP, Steward WP, et al. Combining curcumin (C3-complex, Sabinsa) with standard care FOLFOX chemotherapy in patients with inoperable colorectal cancer (CUFOX): study protocol for a randomised control trial. Trials 2015;16:110.

64. Dhillon N, Aggarwal BB, Newman RA, Wolff RA, Kunnumakkara AB, et al. Phase II trial of curcumin in patients with advanced pancreatic cancer. Clin Cancer Res 2008;14:4491-9.

65. Hawke RL, Schrieber SJ, Soule TA, Wen Z, Smith PC, et al. Silymarin ascending multiple oral dosing phase I study in noncirrhotic patients with chronic hepatitis C. J Clin Pharmacol 2010;50:434-49.

66. Ladas EJ, Kroll DJ, Oberlies NH, Cheng B, Ndao DH, et al. A randomized, controlled, double-blind, pilot study of milk thistle for the treatment of hepatotoxicity in childhood acute lymphoblastic leukemia (ALL). Cancer 2010;116:506-13.

67. Flaig TW, Gustafson DL, Su LJ, Zirrolli JA, Crighton F, et al. A phase I and pharmacokinetic study of silybin-phytosome in prostate cancer patients. Invest New Drugs 2007;25:139-46. 